\title{
Effects of oligofructose-enriched inulin on intestinal absorption of calcium and magnesium and bone turnover markers in postmenopausal women
}

\author{
Leah Holloway $^{1}$, Sharon Moynihan ${ }^{1}$, Steven A. Abrams ${ }^{2}$, Kyla Kent ${ }^{1}$, Andrew R. Hsu ${ }^{1}$ \\ and Anne L. Friedlander ${ }^{1 *}$ \\ ${ }^{1}$ Clinical Studies Unit and Geriatric Research Education and Clinical Center, VA Palo Alto Health Care System, \\ Palo Alto, California, USA \\ ${ }^{2}$ USDA/ARS Children's Nutrition Research Center, Baylor College of Medicine, Houston, Texas, USA
}

(Received 4 January 2006 - Revised 2 August 2006 - Accepted 26 September 2006)

\begin{abstract}
Deficiency of oestrogen at menopause decreases intestinal Ca absorption, contributing to a negative Ca balance and bone loss. Mg deficiency has also been associated with bone loss. The purpose of the present investigation was to test the hypothesis that treatment with a spray-dried mixture of chicory oligofructose and long-chain inulin (Synergy1; SYN1) would increase the absorption of both Ca and Mg and alter markers of bone turnover. Fifteen postmenopausal women (72.2 (SD 6.4) years) were treated with SYN1 or placebo for 6 weeks using a double-blind, placebo-controlled, cross-over design. Fractional $\mathrm{Ca}$ and $\mathrm{Mg}$ absorption were measured using dual-tracer stable isotopes before and after treatment. Bone turnover markers were measured at baseline, 3 and 6 weeks. Fractional absorption of $\mathrm{Ca}$ and $\mathrm{Mg}$ increased following SYN1 compared with placebo $(P<0 \cdot 05)$. Bone resorption (by urinary deoxypyridinoline cross-links) was greater than baseline at 6 weeks of active treatment $(P<0 \cdot 05)$. Bone formation (by serum osteocalcin) showed an upward trend at 3 weeks and an increase following 6 weeks of SYN1 $(P<0 \cdot 05)$. Closer examination revealed a variation in response, with two-thirds of the subjects showing increased absorption with SYN1. Post hoc analyses demonstrated that positive responders had significantly lower lumbar spine bone mineral density than non-responders (dual X-ray absorptiometry $\left.0.887 \pm 0.102 v .1 .104 \pm 0.121 \mathrm{~g} / \mathrm{cm}^{2} ; P<0.01\right)$, and changes in bone turnover markers occurred only in responders. These results suggest that 6 weeks of SYN1 can improve mineral absorption and impact markers of bone turnover in postmenopausal women. Further research is needed to determine why a greater response was found in women with lower initial spine bone mineral density.
\end{abstract}

Synergy1: Mineral absorption: Bone turnover: Bone density: Oligofructose: Inulin

Despite recent advances in the pharmacological prevention and treatment of osteoporosis, women who elect not to take hormone or drug therapy are at particular risk of developing osteoporosis. Thus, there remains a substantial need for additional strategies for maintenance of skeletal health after menopause. Oestrogen deficiency at menopause leads to a decrease in intestinal $\mathrm{Ca}$ absorption and a corresponding increase in renal $\mathrm{Ca}$ excretion, leading to a negative $\mathrm{Ca}$ balance that contributes to bone mineral loss (Prince, 1994). Evidence from clinical trials suggests that an increase in Ca balance will positively affect bone mass and bone mineral density (BMD; Prince et al. 1995). Although Ca supplementation is not as effective as anti-resorptive agents in maintaining BMD, it has been shown to alter the balance of bone turnover markers (Riggs et al. 1998) and to decrease fracture risk in both peri- and postmenopausal women (Report of the North American Menopause Society, 2001). Unfortunately, the solution is not as straightforward as simply consuming more $\mathrm{Ca}$ because the percentage absorption is inversely related to intake (Heaney et al. 1990) so that increasing Ca intake may be partially negated by a corresponding decrease in the efficiency of $\mathrm{Ca}$ absorption.
The primary method of increasing $\mathrm{Ca}$ absorption is by increasing circulating levels of 25 hydroxyvitamin D $(25(\mathrm{OH})$ vitamin D) from 'low normal' to 'high normal' (Heaney et al. 2003). Another possible way to increase fractional $\mathrm{Ca}$ absorption may be through the consumption of non-digestible oligosaccharides such as oligofructose-enriched inulin, a prebiotic carbohydrate (Abrams et al. 2005). Nondigestible oligosaccharides may influence $\mathrm{Ca}$ absorption indirectly by stimulating hypertrophy of the intestinal mucosa, thereby increasing the surface area for diffusion, or directly by increasing transcellular transport through the production of SCFA (Greger, 1999). These fatty acids may decrease $\mathrm{pH}$, thus allowing an additional exchange of $\mathrm{H}$ ions for Ca ions (van den Heuvel et al. 2000; Raschka \& Daniel, 2005). Oligosaccharides have also been shown to increase the absorption of $\mathrm{Mg}$ ions in postmenopausal women (Tahiri et al. 2001). Although the role of $\mathrm{Mg}$ in bone health is less clear, serum and bone $\mathrm{Mg}$ are reduced in postmenopausal women (Yano et al. 1985; Cohen, 1988), and supplementation with $\mathrm{Mg}$ has been shown to increase bone mass in osteoporotic women (Stendig-Lindberg et al. 1993). Therefore, the purpose

Abbreviations: 25(OH) vitamin D, 25 hydroxyvitamin D; BMD, bone mineral density; DP, degree of polymerisation; PTH, parathyroid hormone.

* Corresponding author: Dr Anne L. Friedlander, fax +1 650849 0535, email friedlan@stanford.edu 
of the current investigation was to determine whether a product containing oligofructose from chicory plus long-chain inulin enriched with oligofructose (Synergy1; SYN1) could alter $\mathrm{Ca}$ and $\mathrm{Mg}$ absorption in healthy postmenopausal women. We hypothesised that 6 weeks of treatment with SYN1 would increase the efficiency of intestinal mineral absorption, resulting in a reduction in bone resorption.

\section{Subjects and methods}

\section{Subjects}

Fifteen healthy, free-living postmenopausal women were recruited by letter and flyer from the surrounding community. All participants were a minimum of 10 years past the onset of menopause. Exclusion criteria included use of hormone replacement therapy either currently or within the previous year, use of any pharmacological osteoporosis treatment, use of thiazide diuretics or glucocorticoids, diabetes or any illness known to affect either intestinal absorption or bone metabolism. The protocol was approved by the Stanford University Administrative Panel on Human Subjects in Medical Research and the Institutional Review Board for Human Subject Research of Baylor College of Medicine, and each subject gave written informed consent.

Volunteers underwent a screening visit that included a health history questionnaire, electrocardiogram and routine blood and urine chemistry. At this visit, they were given $3 \mathrm{~d}$ food record forms to complete at home. The records were subsequently analysed using a commercially available software program, Nutritionist V (First DataBank, Inc., San Bruno, CA, USA). Participants with intakes of less than $800 \mathrm{mg} / \mathrm{d}$ $\mathrm{Ca}$ were given a $\mathrm{CaCO}_{3}$ supplement $(500 \mathrm{mg})$ to take for 3 weeks prior to their first study evaluation (equilibrium phase) and for the remainder of the study. No participant had a $\mathrm{Ca}$ intake greater than $1300 \mathrm{mg} / \mathrm{d}$. The data from one subject were deleted from the analysis of mineral absorption due to non-compliance with the urine collection protocol during the 6-week active phase measurement period.

\section{General study design}

Participants were randomised to receive either SYN1 or placebo (completely digestible maltodextrin) in a cross-over fashion for 6 weeks followed by a 6 -week washout period. After the washout period, each subject received the other treatment for an additional 6 weeks. Fasting blood and urine samples were collected at baseline, 3 weeks and 6 weeks of each treatment period for measurement of bone turnover markers parathyroid hormone $(\mathrm{PTH})$ and $25(\mathrm{OH})$ Vitamin D. Measurements were made in the Clinical Studies Unit, VA Palo Alto Health Care System on subjects who had been fasting for 8 or more hours and were well hydrated. Samples were collected between 08.00 and 10.00 hours. Mineral absorption studies were performed at baseline and 6 weeks of each treatment period. Absorption was measured by dual stable isotope on $72 \mathrm{~h}$ urine collections. Bone density of the hip and spine was also measured on each subject by dual X-ray absorptiometry at the Musculo-Skeletal Research Laboratory at the Menlo Park Division of the VA Palo Alto Health Care System.

\section{Intervention treatment}

At the start of each intervention period, subjects received packets of either SYN1 or placebo in a randomised, doubleblind manner. Participants were instructed to consume one packet with breakfast and one packet with dinner for 6 weeks and to record the time of consumption. They were advised that the packet contents would more easily dissolve in a heated liquid, and it was recommended that the packet be taken with coffee or hot tea.

Each active packet contained $5 \mathrm{~g}$ Raftilose Synergy 1 (Orafti, Tienen, Belgium), which is a co-spray dried 1:1 mixture of chicory oligofructose (a $\beta(2-1)$ chicory fructan with a degree of polymerisation (DP) of 3-8, average DP 4) and long-chain inulin (a $\beta$ (2-1) chicory fructan with DP 10-65, average DP 25). The commercial SYN1 product contains $92 \%$ fructans and $8 \%$ sugars (glucose, fructose, sucrose; Van Loo, 2004). Inulin (DP 3-65, average DP 10) is extracted from chicory roots with hot water. Inulin is present as a storage carbohydrate in such foods as leeks, onions, bananas, garlic and wheat (Van Loo et al. 1995). It is resistant to absorption in the small intestine and arrives in the colon where it is selectively fermented. Oligofructose (DP 3-8, average DP 4) is produced by means of a partial enzymatic hydrolysis of inulin. A long-chain inulin fraction (DP 12-65, average DP 25) is extracted from inulin by means of a physicochemical separation technique. SYN1 is a 1:1 combination of oligofructose and the long-chain inulin fraction (Coudray et al. 2003). The placebo packets contained a digestible matodextrin.

\section{Calcium and magnesium absorption testing}

$\mathrm{Ca}$ and $\mathrm{Mg}$ absorption were measured at baseline and at 6 weeks of each treatment period. To measure absorption, each subject was given $22 \mu \mathrm{g}$ stable isotope ${ }^{46} \mathrm{Ca}$ and $23 \mathrm{mg}$ ${ }^{26} \mathrm{Mg}$ in $118 \mathrm{ml} \mathrm{Ca-fortified} \mathrm{orange} \mathrm{juice} \mathrm{as} \mathrm{part} \mathrm{of} \mathrm{a} \mathrm{test}$ meal. The remainder of the standardised test meal consisted of an English muffin with one pat of margarine and one pat of jelly, 118 additional $\mathrm{ml}$ Ca-fortified orange juice and $237 \mathrm{ml}$ decaffeinated coffee or tea, providing a total intake of $396 \mathrm{mg} \mathrm{Ca}$ and $58 \mathrm{mg} \mathrm{Mg}$. The time of completion of the test meal was recorded. Subjects were then given $1.2 \mathrm{mg}$ ${ }^{42} \mathrm{Ca}$ and $11.5 \mathrm{mg}{ }^{25} \mathrm{Mg}$ intravenously over a $30 \mathrm{~min}$ period. The intravenous line was flushed with saline after the stable isotopes had been given. Subjects were discharged with collection supplies and an additional $118 \mathrm{ml} \mathrm{Ca-fortified} \mathrm{orange}$ juice to be consumed with dinner. All voided urine was collected for the next $72 \mathrm{~h}$ in two $36 \mathrm{~h}$ collection periods. During the $72 \mathrm{~h}$ collection period, food intake was recorded using the $3 \mathrm{~d}$ food records. These were analysed for $\mathrm{Ca}$ and $\mathrm{Mg}$ intake using Nutritionist V.

\section{Calcium and magnesium absorption analyses}

$\mathrm{Ca}$ and $\mathrm{Mg}$ absorption analyses were performed at Baylor College of Medicine Houston, Texas, USA. Ca samples were prepared for mass spectrometric analysis using an oxalate precipitation technique (Yergey et al. 1980). Mg samples were prepared using cation exchange chromatography (Vieira et al. 1994). Ca isotopic ratios were measured using magnetic 
sector thermal ionisation mass spectrometry (MAT 261; Finnigan, Bremen, Germany). Mg samples were analysed by inductively coupled plasma mass spectrometry (ICP-MS) (Vieira et al. 1994). A ratio was calculated between each Ca isotope and ${ }^{43} \mathrm{Ca}$, and each $\mathrm{Mg}$ isotope and ${ }^{24} \mathrm{Mg}$.

\section{Bone mineral density measurements}

BMD in the lumbar spine (L2-L4) and hip was measured using dual X-ray absorptiometry (QDR 4000; Hologic, Waltham, MA, USA). The long-term precision of these measurements in our laboratory is $1.5 \%$ at each site for this age group. To reduce the precision error, duplicate measurements were obtained and mean values analysed. Dual X-ray absorptiometry measurements were made in the Musculoskeletal Research Center at the Menlo Park Division of the VA Palo Alto Health Care System.

\section{Biochemical analyses}

Fasting serum and urine samples were stored at $-70^{\circ} \mathrm{C}$ until analysed. All biochemical analyses were run on batched specimens in a single-assay run. Human osteocalcin in serum was measured using a commercially available twosite immunoradiometric assay (Diagnostic Systems Laboratories, Inc., Webster, TX, USA). Urinary deoxypyridinoline cross-links were measured using a competitive enzyme immunoassay kit (Quidel Corp., San Diego, CA, USA) and corrected for urine creatinine. Urine creatinine was measured with a quantitative, colorimetric assay (Quidel Corp). Serum intact PTH was measured using an immunoradiometric assay (Diagnostic Systems Laboratories, Inc,). Serum 25(OH) vitamin D concentrations were measured following extraction with $\mathrm{NaOH}$ and acetonitrile using an RIA (IDS Ltd, Boldon, Tyne \& Wear, UK).

\section{Statistics}

Data were analysed using Statview II (Abacus Concepts, Berkeley, CA, USA). Values are presented as mean and their standard errors except where noted. Changes from baseline were calculated for treatment and placebo interventions, and comparisons between interventions were analysed using paired $t$ tests. For multiple time points, ANOVA with repeat measures (treatment $\times$ time) were used. When appropriate, post hoc tests for significance were made using Fisher's least significant difference test. Significance was set at $P<0.05$.

\section{Results}

\section{Subjects}

Fifteen subjects successfully completed the study. One subject was, however, excluded from the analysis owing to non-compliance with the urine collection protocol during the active-phase measurement period. In addition, bone turnover markers and markers of the PTH-vitamin D axis were not measured in an additional subject owing to logistical issues. The baseline characteristics of the subjects are presented in Table 1. There were no significant differences in any measured variable at baseline visits between the active and the placebo treatment period. All subjects were determined to be vitamin $\mathrm{D}$ replete as measured by $25(\mathrm{OH})$ vitamin $\mathrm{D}$ concentration using currently accepted reference ranges.

\section{Calcium and magnesium absorption}

True absorption of Ca demonstrated a significant increase after treatment with SYN1 (Table 2). In addition, the change in absorption in the active compared with the placebo group was greater for both $\mathrm{Ca}(+5 \cdot 1(\operatorname{SE} 2 \cdot 1) \% v$. $-3 \cdot 3$ (SE 2.2); $P<0.05)$ and $\mathrm{Mg}(+5.2$ (SE 2.9) \% $v$. -4.3 (SE 3.0); $P<0.05)$. Analyses of starting baseline values and changes in the absorption of $\mathrm{Ca}$ and $\mathrm{Mg}$ for each phase revealed no order effects or carry-over between treatments.

\section{Markers of bone turnover}

Deoxypyridinoline cross-links, an index of bone resorption activity, showed an initial transient decrease at 3 weeks in the SYN1 group $(P=0.08)$ but rebounded to levels greater than baseline by 6 weeks of treatment $(P<0.05 v$. baseline $)$. There was no significant change in the placebo group and no significant difference between treatments (Fig. 1). Levels of serum osteocalcin, a measure of bone formation activity, were increased at 6 weeks of treatment only in the SYN1 group (Fig. 2).

\section{Vitamin D-parathyroid axis}

Changes in PTH and $25(\mathrm{OH})$ vitamin D were measured after 3 and 6 weeks of treatment. There was a non-significant decrease in PTH at 6 weeks in the SYN1-treated group (Fig. 3). No change was observed after 6 weeks of placebo. The average baseline concentration of $25(\mathrm{OH})$ vitamin $\mathrm{D}$ was $25 \mathrm{ng} / \mathrm{ml}$ and did not change significantly with treatment in either group.

\section{Post hoc analysis}

Post hoc examination of the data showed that there was a difference in the response to SYN1 between the subjects. For both $\mathrm{Ca}$ and $\mathrm{Mg}$, approximately two-thirds of the subjects demonstrated an increase in absorption after treatment, whereas the remaining subjects did not (Fig. 4). Differences in response were not a function of initial absorption values as baseline $\mathrm{Mg}$ and $\mathrm{Ca}$ absorption was no different between

Table 1. Baseline characteristics by treatment group (Mean values and standard deviations)

\begin{tabular}{|c|c|c|c|c|}
\hline \multirow[b]{2}{*}{ Variable } & \multicolumn{2}{|c|}{ SYN1 } & \multicolumn{2}{|c|}{ Placebo } \\
\hline & Mean & SD & Mean & SD \\
\hline Age (years) & $72 \cdot 2$ & $6 \cdot 4$ & $72 \cdot 2$ & $6 \cdot 4$ \\
\hline Time since menopause (years) & $24 \cdot 7$ & $9 \cdot 7$ & 24.7 & $9 \cdot 7$ \\
\hline Body mass index $\left(\mathrm{kg} / \mathrm{m}^{2}\right)$ & $25 \cdot 1$ & $3 \cdot 3$ & $25 \cdot 3$ & $3 \cdot 2$ \\
\hline Ca intake $(\mathrm{mg} / \mathrm{d})$ & 1086 & 232 & 1018 & 251 \\
\hline Ca supplementation $(n, \%)$ & $6,43 \%$ & & $6,43 \%$ & \\
\hline Mg intake (mg/d) & 298 & 136 & 260 & 98 \\
\hline 25 hydroxyvitamin $\mathrm{D}(\mathrm{ng} / \mathrm{ml})$ & $25 \cdot 0$ & 8.4 & 24.3 & 8.0 \\
\hline
\end{tabular}


Table 2. Ca and $\mathrm{Mg}$ absorption values before and after treatment (Means and their standard errors for fourteen determinations)

\begin{tabular}{|c|c|c|c|c|c|c|c|c|c|c|c|c|}
\hline \multirow[b]{2}{*}{ True absorption (\%) } & \multicolumn{2}{|c|}{ Baseline } & \multicolumn{2}{|c|}{ SYN1 } & \multicolumn{2}{|c|}{ Change } & \multicolumn{2}{|c|}{ Baseline } & \multicolumn{2}{|c|}{ Placebo } & \multicolumn{2}{|c|}{ Change } \\
\hline & Mean & SE & Mean & SE & Mean & SE & Mean & SE & Mean & SE & Mean & SE \\
\hline $\mathrm{Ca} a b$ & $22 \cdot 2$ & 2.9 & $27 \cdot 3$ & $4 \cdot 2$ & $5 \cdot 1$ & $2 \cdot 1^{*} \dagger$ & $24 \cdot 1$ & 1.7 & $20 \cdot 8$ & $2 \cdot 4$ & -3.3 & $2 \cdot 2$ \\
\hline Mg absorption & 51.5 & $3 \cdot 0$ & $56 \cdot 7$ & $3 \cdot 2$ & $5 \cdot 2$ & $2 \cdot 9^{*}$ & $54 \cdot 6$ & $2 \cdot 6$ & $50 \cdot 4$ & 1.7 & -4.3 & 3.0 \\
\hline
\end{tabular}

* Significantly different from placebo $(P<0.05)$.

† Significantly different from baseline $(P<0.05)$.

positive and negative responders. Ca supplementation was also equally distributed between the two groups, and baseline $\mathrm{Ca}$ and $\mathrm{Mg}$ intake levels did not differ between responder groups. BMD of the lumbar spine was, however, significantly lower in responders compared with non-responders (Fig. 5). Although it is unclear what role normal $\mathrm{Mg}$ levels play in bone, it is interesting to note that there was a strong correlation $(r=0.777, P<0.001)$ between baseline bone turnover and response in $\mathrm{Mg}$ absorption to treatment with SYN1. In contrast, there was no relationship between baseline bone turnover and the response in Ca absorption $(r=0 \cdot 133, \mathrm{NS})$.

\section{Discussion}

The major finding of this investigation was that 6 weeks of treatment with SYN1 in postmenopausal women resulted in a significant increase in both $\mathrm{Ca}$ and $\mathrm{Mg}$ absorption relative to the placebo treatment. We hypothesised that the increase in mineral absorption would be followed by a corresponding decrease in bone turnover. Although the bone marker results were not completely clear, a positive balance in formation relative to resorption did seem to be evident at the intermediate 3-week time point. Despite the significant group changes in mineral absorption, there was substantial variability in individual responses to treatment, with the majority of subjects responding by increasing mineral absorption in response to SYN1 treatment, and a subset who did not. Similar patterns have previously been noted in response to oligosaccharide treatment in postmenopausal women (Tahiri et al. 2001, 2003). Although reasons for the differences between individuals cannot be definitely

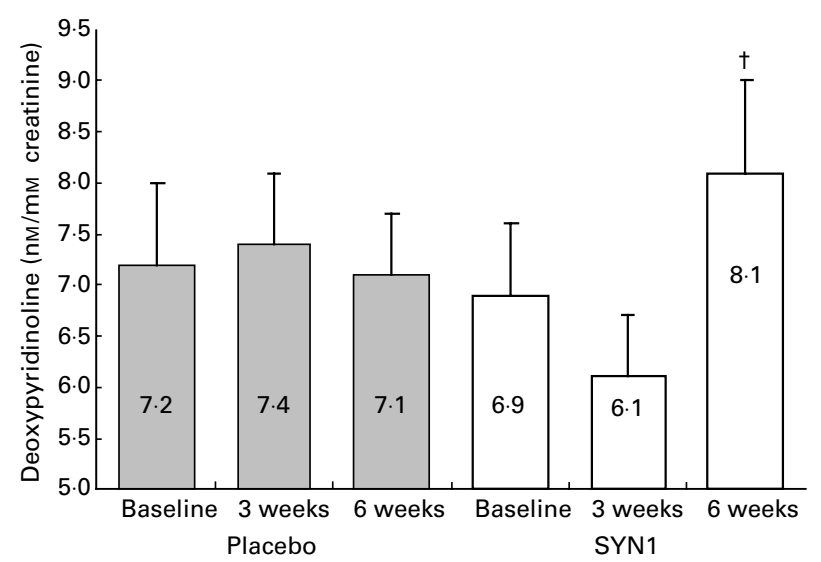

Fig. 1. Effect of 6 weeks of treatment with SYN1 or placebo on bone resorption as estimated by urinary deoxypyridinoline cross-link concentration corrected for urinary creatinine. + Significantly different from baseline $(P<0.05)$. determined from these data, subjects who responded positively to treatment did have lower lumbar spine BMD values than non-responders. A relationship between initial BMD values, bone turnover markers and responsiveness to treatment has previously been described in investigations using some antiresorptive treatments for osteoporosis (Gennari et al. 1992).

\section{Calcium absorption}

We observed a significant increase in Ca absorption with nondigestible oligosaccharide treatment in this investigation even though vitamin $\mathrm{D}$ status was adequate and $\mathrm{Ca}$ intake was good. In rats, it has been demonstrated that treatment with non-digestible fructans successfully increases $\mathrm{Ca}$ absorption and results in a corresponding increase in bone mineral (Delzenne et al. 1995; Takahara et al. 2000; Roberfroid et al. 2002; Scholz-Ahrens et al. 2002; Coudray et al. 2003). Similarly, boys given $15 \mathrm{~g}$ chicory oligofructose for $9 \mathrm{~d}$ demonstrated increased fractional $\mathrm{Ca}$ absorption as measured by a dual-isotope technique (van den Heuvel et al. 1999). In young girls, 3 weeks of treatment with either $8 \mathrm{~g} / \mathrm{d}$ sucrose, oligofructose or SYN1 caused a significant increase in $\mathrm{Ca}$ absorption in the group given SYN1 compared with the sucrose group. No significant increase in $\mathrm{Ca}$ absorption with oligofructose alone was, however, reported (Griffin et al. 2002). The importance of chain length of the chicory fructans on $\mathrm{Ca}$ absorption has been demonstrated by Coudray et al. (2003). Furthermore, a larger-scale intervention ( $n$ 100; placebo and SYN1 $8 \mathrm{~g} / \mathrm{d}$ ) for 1 year conducted in prepubescent

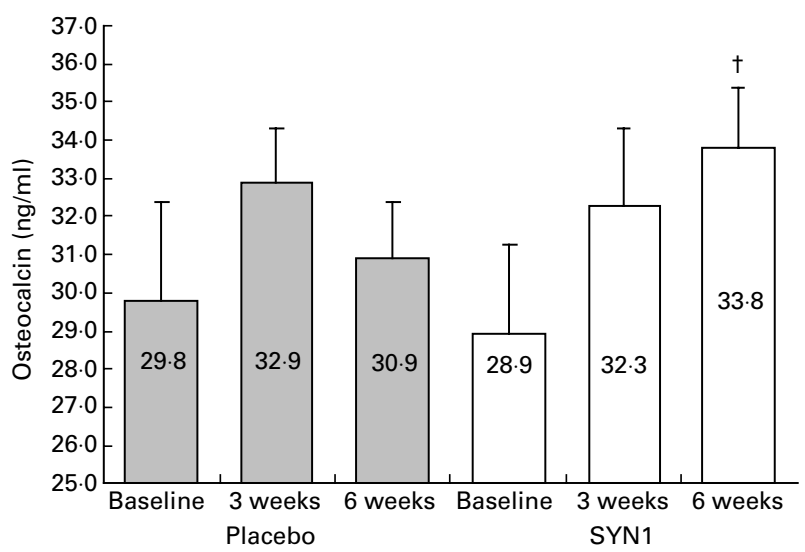

Fig. 2. Effect of 6 weeks of treatment with SYN1 or placebo on bone formation as estimated by serum osteocalcin concentration. †Significantly different from baseline $(P<0.05)$. 


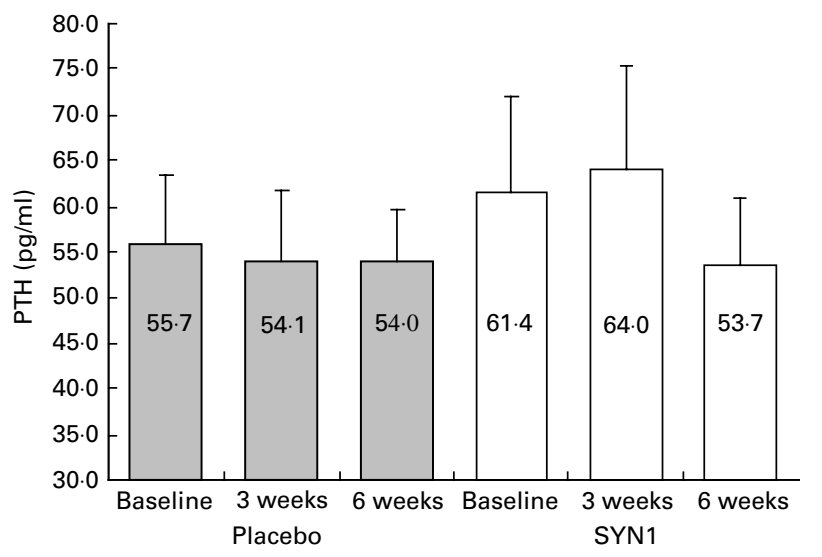

Fig. 3. Effect of 6 weeks of treatment with SYN1 or placebo on parathyroid hormone (PTH).

children demonstrated that the increase in mineral absorption observed after 8 weeks of SYN1 treatment was also evident at 1 year and was associated with enhanced bone mineralisation (Abrams et al. 2005).

The presence of oestrogen receptors in the intestine supports the theory that oestrogen may directly increase intestinal Ca absorption (Thomas et al. 1993; Prince, 1994). Heaney et al. (1989) have estimated that the combined effect of ageing and oestrogen withdrawal at menopause produces a decline in absorptive performance of $20-25 \%$ over a 20-year period. Therefore, postmenopausal women could benefit the most from any agent that increases $\mathrm{Ca}$ absorption and the $\mathrm{Ca}$ load on the system. Indeed, nondigestible oligosaccharide treatment in postmenopausal women has yielded promising results so far. For example, increased $\mathrm{Ca}$ absorption has been reported in postmenopausal women treated with $20 \mathrm{~g} / \mathrm{d}$ transgalacto-oligosaccharides for $9 \mathrm{~d}$ (van den Heuvel et al. 2000). Although this study utilised a slightly different non-digestible oligosaccharide, the changes observed were similar to those observed in the current investigation.

In contrast to the above studies, a study by Tahiri et al. (2003) reported that postmenopausal women treated with non-digestible fructans for 5 weeks $(5 \mathrm{~g} / \mathrm{d}$ for the first $4 \mathrm{~d}$, $10 \mathrm{~g} / \mathrm{d}$ for the remainder) showed no increase in Ca absorption. The authors postulate that there was an earlier increase in $\mathrm{Ca}$ absorption due to treatment, but that the active pathway was downregulated by a feedback mechanism, effectively decreasing $\mathrm{Ca}$ absorption to pretreatment levels in order to maintain serum $\mathrm{Ca}$ levels within a narrow range. This feedback mechanism may be mediated by a reduction in 1,25 dihydroxyvitamin $\mathrm{D}$ followed by a fall in Ca-binding protein. Although the explanation is feasible, we were able to show a significant effect at 6 weeks. As suggested in the study on young girls (Griffin et al. 2002), it is possible that the addition of inulin to the oligofructose (SYN1) helped to augment the response in mineral absorption.

\section{Magnesium absorption}

Mechanisms exist in the intestine and kidney to regulate $\mathrm{Mg}$ homeostasis closely. In the intestine, an active transport
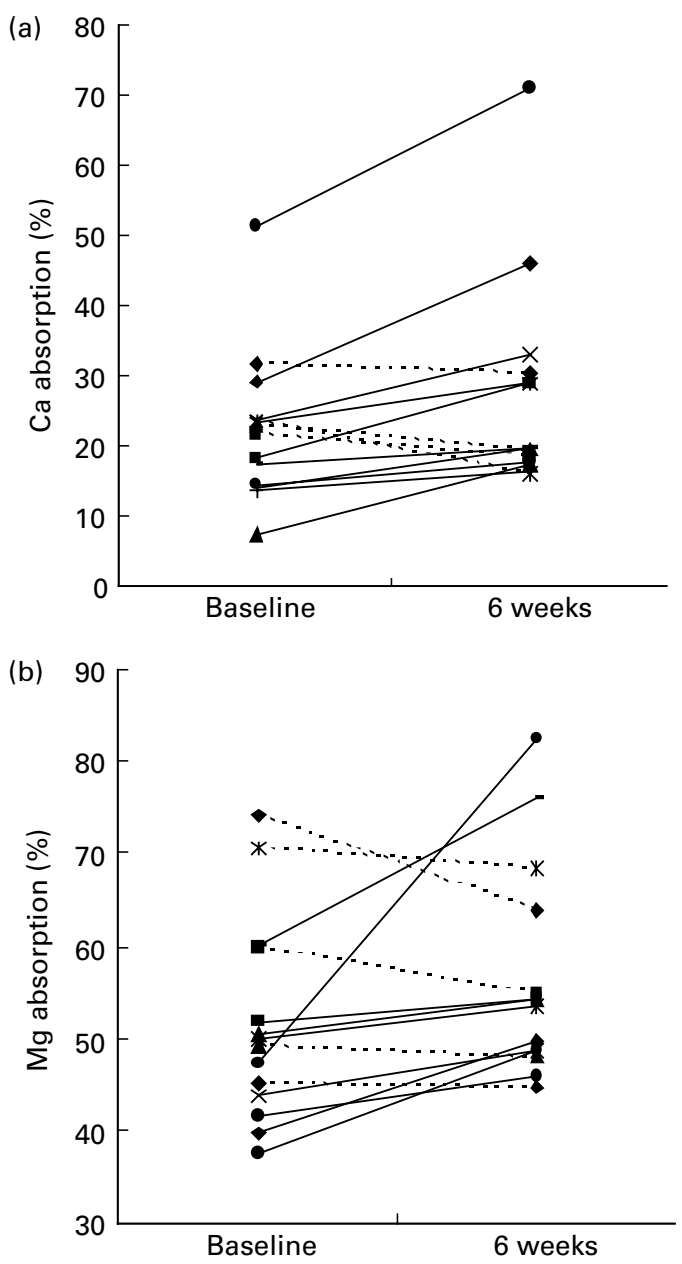

Fig. 4. Individual changes of (a) $\mathrm{Ca}$ and (b) $\mathrm{Mg}$ absorption in response to active treatment (SYN1).

system increases fractional absorption at low intake levels (Kayne \& Lee, 1993). Some studies have indicated that postmenopausal women with osteoporosis have a significant reduction in $\mathrm{Mg}$ level in both serum and bone relative to age-matched controls (Cohen, 1988; Reginster et al. 1989). Other studies have found no such relationship (Yano et al. 1985). Large changes in blood $\mathrm{Mg}$ concentration acutely affect PTH secretion in a similar way to $\mathrm{Ca}$ (Rude et al. 1978). Furthermore, treatment with 1 year of $\mathrm{Mg}$ supplements has been reported to increased bone mass in osteoporotic postmenopausal women (Stendig-Lindberg et al. 1993). Therefore, $\mathrm{Mg}$ availability may be a contributor to bone health. Studies investigating the effect of chicory fructans on $\mathrm{Mg}$ absorption have yielded conflicting results. Adolescents (van den Heuvel et al. 1999) and young adult men (Coudray et al. 1997) showed no increase in $\mathrm{Mg}$ absorption when treated for $9 \mathrm{~d}$ and 4 weeks, respectively. However, similar to our data, Tahiri et al. (2001) reported positive results when treating eleven postmenopausal women with non-digestible fructooligosaccharides for 5 weeks, suggesting that postmenopausal 


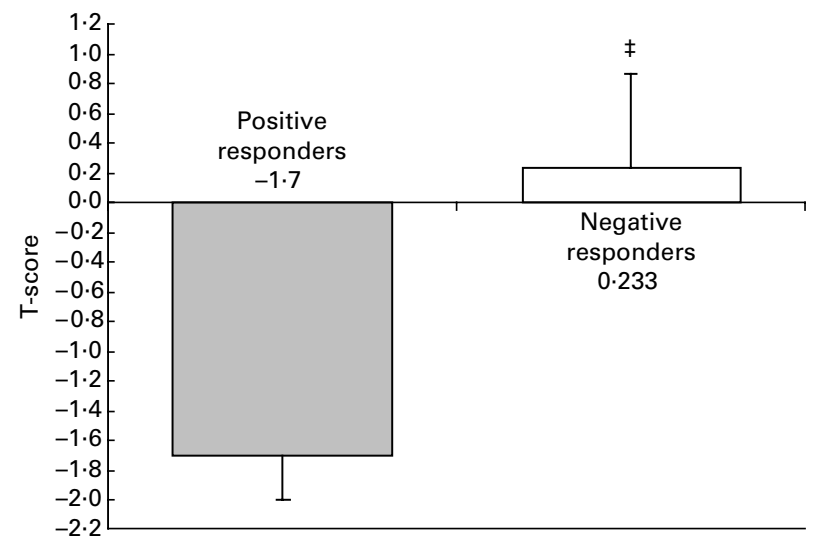

Fig. 5. Baseline lumbar spine T-score in responders and non-responders for $\mathrm{Ca}$ absorption. $¥$ Significantly different from positive responders $(P<0.05)$.

women may be more susceptible to the benefits of fructans on $\mathrm{Mg}$ absorption than other populations studied.

\section{Bone turnover}

Consistent with the many studies that show a decrease in bone resorption following an increase in Ca intake (Ginty et al. 1998; Scopacasa et al. 1998, 2002; Jensen et al. 2002), the initial decrease in deoxypyridinoline that was observed with SYN1 treatment was as expected. Similarly, Tahiri et al. (2001) demonstrated a non-significant decrease in deoxypyridinoline in postmenopausal women after 5 weeks of treatment with non-digestible fructo-oligosaccharides. More complicated is our observation that resorption values rebounded to a level greater than at baseline by 6 weeks of treatment with SYN1. It may be that the peak rise in $\mathrm{Ca}$ absorption occurred earlier than 6 weeks and thus was falling by the 6 -week measurement period as previously suggested (Tahiri et al. 2003).

In the normal 'coupled' bone system, a decrease in resorption is followed by a decrease in formation (Eastell et al. 1993). In our study, it seems that formation became temporarily 'uncoupled' from resorption. Some pharmacological treatments, such as intermittent doses of PTH, owe their anabolic effect to an initial 'uncoupled' increase in bone formation. Anti-resorptive agents slow resorption but also slow formation. If SYN1 temporarily increased formation while at the same time decreasing resorption, a net gain in bone mineral might result. Caution should, however, be used when applying physiological significance to the changes in bone markers observed in this investigation. The changes were small, short term and, based on data by Hannon et al. (1998), less than the 'least significant change' value of greater than $25 \%$ that was calculated from the within-subject variability of deoxypyridinoline and osteocalcin determined in similar postmenopausal women.

\section{Parathyroid hormone}

After 6 weeks of SYN1 treatment, we observed a non-significant decrease in PTH. Oral $\mathrm{Ca}$ doses of $1 \mathrm{~g}$ immediately increase serum ionised Ca and suppress PTH (Herfarth et al. 1992; Karkkainen et al. 2001) with a duration of effect of
8-10 h (Blumsohn et al. 1994). Ca intake at a single meal is generally less than $500 \mathrm{mg}$, but even smaller Ca doses of $250 \mathrm{mg}$ have been shown to increase ionised $\mathrm{Ca}$ and decrease circulating PTH (Karkkainen et al. 2001). The timing of $\mathrm{Ca}$ intake also appears to be important as it has been shown that dividing a dose of $\mathrm{Ca}$ over $6 \mathrm{~h}$ prolonged the decrease in serum PTH (Reginster et al. 2002). With an average intake of $1000 \mathrm{mg} / \mathrm{d}$, we would expect to see spikes of ionised $\mathrm{Ca}$ and a depression of PTH level following each meal. In our study, however, the blood for analysis of PTH was taken after a fast of at least $10 \mathrm{~h}$, minimising our ability to detect the acute effect of Ca intake on circulating PTH level. The timing of our measurement may also explain why there was no significant correlation between change in $\mathrm{Ca}$ absorption and change in PTH at 6 weeks.

\section{Vitamin D}

The response threshold for vitamin $\mathrm{D}$ has been described as the serum level of $25(\mathrm{OH})$ vitamin $\mathrm{D}$ at which changes in intake no longer have an effect on the efficiency of $\mathrm{Ca}$ absorption. Although the exact threshold level has yet to be determined, it is estimated to be approximately $35 \mathrm{ng} / \mathrm{ml}$, higher than the previously recommended low end of the reference range of 15-20 ng/ml. In a recent study (Heaney et al. 2003), Ca absorption efficiency increased by $45-65 \%$ when serum levels of $25(\mathrm{OH})$ vitamin D were augmented from the low end of the current reference range to the mid-range (from $20 \mathrm{ng} / \mathrm{ml}$ to $35 \mathrm{ng}$ / $\mathrm{ml}$ ), suggesting that the reference range should be adjusted. Although all of the women in this study had circulating levels of $25(\mathrm{OH})$ vitamin $\mathrm{D}$ of $15 \mathrm{ng} / \mathrm{ml}$ or higher, only two had levels greater than $35 \mathrm{ng} / \mathrm{ml}$. It is therefore possible that, with a larger sample size, the variability in mineral absorption response could be partially explained by the differences in vitamin D status. Further research should be carried out to identify the combined effect of vitamin D and chicory fructans on $\mathrm{Ca}$ and $\mathrm{Mg}$ absorption.

\section{Conclusion}

This investigation suggests that 6 weeks of treatment with $10 \mathrm{~g} / \mathrm{d}$ SYN1 in postmenopausal women can significantly increase $\mathrm{Ca}$ and $\mathrm{Mg}$ absorption relative to placebo treatment of the same duration. Although the markers of bone turnover did not demonstrate a clear pattern in response to the increased mineral absorption, there was a short-term decrease in the marker of bone resorption. Future investigations focusing on the optimal duration and timing of treatment may help to validate the potential benefits of SYN1 consumption on bone health. This should be investigated in long-term studies in which bone density is the central biomarker.

\section{Acknowledgements}

We thank the subjects for their participation, the nurses in the Clinical Studies Unit for their assistance with the subject testing, and Lily Liang for her laboratory assistance with the mineral absorption data. This project was supported by a grant from Orafti Active Food Ingredient. 


\section{References}

Abrams SA, Griffin IJ, Hawthorne KM, Liang L, Gunn SK, Darlington G \& Ellis KJ (2005) A combination of prebiotic short- and long-chain inulin-type fructans enhances calcium absorption and bone mineralization in young adolescents. Am J Clin Nutr 82, 471-476.

Blumsohn A, Herrington K, Hannon RA, Shao P, Eyre DR \& Eastell R (1994) The effect of calcium supplementation on the circadian rhythm of bone resorption. J Clin Endocrinol Metab 79, $730-735$.

Cohen L (1988) Recent data on magnesium and osteoporosis. Magnes Res 1, 85-87.

Coudray C, Bellanger J, Castiglia-Delavaud C, Remesy C, Vermorel M \& Rayssignuier Y (1997) Effect of soluble or partly soluble dietary fibres supplementation on absorption and balance of calcium, magnesium, iron and zinc in healthy young men. Eur J Clin Nutr 51, 375-380.

Coudray C, Tressol JC, Gueux E \& Rayssiguier Y (2003) Effects of inulin-type fructans of different chain length and type of branching on intestinal absorption and balance of calcium and magnesium in rats. Eur J Nutr 42, 91-98.

Delzenne N, Aertssens J, Verplaetse H, Roccaro M \& Roberfroid M (1995) Effect of fermentable fructo-oligosaccharides on mineral, nitrogen and energy digestive balance in the rat. Life Sci $\mathbf{5 7}$, $1579-1587$.

Eastell R, Robins SP, Colwell T, Assiri AM, Riggs BL \& Russell RG (1993) Evaluation of bone turnover in type I osteoporosis using biochemical markers specific for both bone formation and bone resorption. Osteoporos Int 3, 255-260.

Gennari C, Agnusdei D, Montagnani M, Gonnelli S \& Civitelli R (1992) An effective regimen of intranasal salmon calcitonin in early postmenopausal bone loss. Calcif Tissue Int 50, 381-383.

Ginty F, Flynn A \& Cashman KD (1998) The effect of short-term calcium supplementation on biochemical markers of bone metabolism in healthy young adults. Br J Nutr 80, 437-443.

Greger JL (1999) Nondigestible carbohydrates and mineral bioavailability. J Nutr 129, 1434S-1435S

Griffin IJ, Davila PM \& Abrams SA (2002) Non-digestible oligosaccharides and calcium absorption in girls with adequate calcium intakes. Br J Nutr 87, Suppl. 2, S187-S191.

Hannon R, Blumsohn A, Naylor K \& Eastell R (1998) Response of biochemical markers of bone turnover to hormone replacement therapy: impact of biological variability. J Bone Miner Res 13, $1124-1133$.

Heaney RP, Dowell MS, Hale CA \& Bendich A (2003) Calcium absorption varies within the reference range for serum 25-hydroxyvitamin D. J Am Coll Nutr 22, 142-146.

Heaney RP, Recker RR, Stegman MR \& Moy AJ (1989) Calcium absorption in women: relationships to calcium intake, estrogen status, and age. J Bone Miner Res 4, 469-475.

Heaney RP, Weaver CM \& Fitzsimmons ML (1990) Influence of calcium load on absorption fraction. J Bone Miner Res 5, 1135-1138.

Herfarth K, Drechsler S, Imhoff W, Schlander M, Engelbach M, Maier A \& Schmidt-Gayk H (1992) Calcium regulating hormones after oral and intravenous calcium administration. Eur J Clin Chem Clin Biochem 30, 815-822.

Jensen C, Holloway L, Block G, Spiller G, Gildengorin G, Gunderson E, Butterfield G \& Marcus R (2002) Long-term effects of nutrient intervention on markers of bone remodeling and calciotropic hormones in late-postmenopausal women. Am J Clin Nutr 75, 1114-1120.

Karkkainen MU, Lamberg-Allardt CJ, Ahonen S \& Valimaki M (2001) Does it make a difference how and when you take your calcium? The acute effects of calcium on calcium and bone metabolism. Am J Clin Nutr 74, 335-342.
Kayne LH \& Lee DB (1993) Intestinal magnesium absorption. Miner Electrolyte Metab 19, 210-217.

Prince R, Devine A, Dick I, Criddle A, Kerr D, Kent N, Price R \& Randell A (1995) The effects of calcium supplementation (milk powder or tablets) and exercise on bone density in postmenopausal women. J Bone Miner Res 10, 1068-1075.

Prince RL (1994) Counterpoint: estrogen effects on calcitropic hormones and calcium homeostasis. Endocr Rev 15, 301-309.

Raschka L \& Daniel H (2005) Mechanisms underlying the effects of inulin-type fructans on calcium absorption in the large intestine of rats. Bone 37, 728-735.

Reginster JY, Strause L, Deroisy R, Lecart MP, Saltman P \& Franchimont P (1989) Preliminary report of decreased serum magnesium in postmenopausal osteoporosis. Magnesium 8, 106-109.

Reginster JY, Zegels B, Lejeune E, Micheletti MC, Kvsaz A, Seidel L \& Sarlet N (2002) Influence of daily regimen calcium and vitamin D supplementation on parathyroid hormone secretion. Calcif Tissue Int 70, 78-82.

Report of the North American Menopause Society (2001) The role of calcium in peri- and postmenopausal women: consensus opinion of The North American Menopause Society. Menopause: The Journal of the North American Menopause Society 8, 84-95.

Riggs BL, O'Fallon WM, Muhs J, O'Connor MK, Kumar R \& Melton LJ 3rd (1998) Long-term effects of calcium supplementation on serum parathyroid hormone level, bone turnover, and bone loss in elderly women. J Bone Miner Res 13, 168-174.

Roberfroid MB, Cumps J \& Devogelaer JP (2002) Dietary chicory inulin increases whole-body bone mineral density in growing male rats. J Nutr 132, 3599-3602.

Rude RK, Oldham SB, Sharp CF Jr \& Singer FR (1978) Parathyroid hormone secretion in magnesium deficiency. $J$ Clin Endocrinol Metab 47, 800-806.

Scholz-Ahrens KE, Acil Y \& Schrezenmeir J (2002) Effect of oligofructose or dietary calcium on repeated calcium and phosphorus balances, bone mineralization and trabecular structure in ovariectomized rats. Br J Nutr 88, 365-377.

Scopacasa F, Horowitz M, Wishart JM, Need AG, Morris HA, Wittert G \& Nordin BE (1998) Calcium supplementation suppresses bone resorption in early postmenopausal women. Calcif Tissue Int 62, 8-12.

Scopacasa F, Need AG, Horowitz M, Wishart JM, Morris HA \& Nordin BE (2002) Effects of dose and timing of calcium supplementation on bone resorption in early menopausal women. Horm Metab Res 34, 44-47.

Stendig-Lindberg G, Tepper R \& Leichter I (1993) Trabecular bone density in a two year controlled trial of peroral magnesium in osteoporosis. Magnes Res 6, 155-163.

Tahiri M, Tressol JC, Arnaud J, et al. (2001) Five-week intake of short-chain fructo-oligosaccharides increases intestinal absorption and status of magnesium in postmenopausal women. $J$ Bone Miner Res 16, 2152-2160.

Tahiri M, Tressol JC, Arnaud J, et al. (2003) Effect of short-chain fructooligosaccharides on intestinal calcium absorption and calcium status in postmenopausal women: a stable-isotope study. Am J Clin Nutr 77, 449-457.

Takahara S, Morohashi T, Sano T, Ohta A, Yamada S \& Sasa R (2000) Fructooligosaccharide consumption enhances femoral bone volume and mineral concentrations in rats. J Nutr 130, 1792-1795.

Thomas ML, Xu X, Norfleet AM \& Watson CS (1993) The presence of functional estrogen receptors in intestinal epithelial cells. Endocrinology 132, 426-430.

van den Heuvel EG, Muys T, van Dokkum W \& Schaafsma G (1999) Oligofructose stimulates calcium absorption in adolescents. Am J Clin Nutr 69, 544-548.

van den Heuvel EG, Schoterman MH \& Muijs T (2000) Transgalactooligosaccharides stimulate calcium absorption in postmenopausal women. J Nutr 130, 2938-2942. 
Van Loo JA (2004) Prebiotics promote good health: the basis, the potential, and the emerging evidence. J Clin Gastroenterol 38, S70-S75.

Van Loo J, Coussement P, de Leenheer L, Hoebregs H \& Smits G (1995) On the presence of inulin and oligofructose as natural ingredients in the western diet. Crit Rev Food Sci Nutr 35, 525-552.

Vieira NE, Yergey AL \& Abrams SA (1994) Extraction of magnesium from biological fluids using 8-hydroxyquinoline and cation-exchange chromatography for isotopic enrichment analysis using thermal ionization mass spectrometry. Anal Biochem 218, 92-97.

Yano K, Heilbrun LK, Wasnich RD, Hankin JH \& Vogel JM (1985) The relationship between diet and bone mineral content of multiple skeletal sites in elderly Japanese-American men and women living in Hawaii. Am J Clin Nutr 42, 877-888.

Yergey AL, Vieira NE \& Hansen JW (1980) Isotope ratio measurements of urinary calcium with a thermal ionization probe in a quadrupole mass spectrometer. Anal Chem 52, 1811-1814. 